\title{
CLOSED CITY LA PRIMAVERA
}

\author{
Sylvia Cristina Rodríguez González ${ }^{1}$ \\ Programa de doctorado "Ciudad, Territorio y Sustentabilidad" \\ Universidad de Guadalajara
}

Remisión Artículo: 21-01-2008

Remisión definitiva: 15-02-2008

Resumen: En la actualidad, el proceso de crecimiento urbano ante la globalización va ligado al fenómeno de expansión urbana, como primer proceso de la tendencia expansióndensificación, la cual se distingue por sus manifestaciones en la problemática urbana.

Esta tendencia estimula el cambio morfológico de las ciudades, especialmente por nuevos desarrollos habitacionales de tipo cerrado, donde la delimitación del conjunto es la muralla. El fenómeno de expansión urbana, a su vez, se distingue por elementos estructurales de la ciudad como vías rápidas, y por el énfasis en las dinámicas de articulación del territorio por nuevas urbanizaciones.

Como el caso La Primavera, el cual constituye un elemento autónomo a la ciudad de Culiacán, Sinaloa, en México, conformando una ciudad urbanizada de tipo cerrada, con gran extensión, pretensiones plasmadas en el proyecto en el que se plantea una multifuncionalidad dirigida a satisfacer las necesidades de estratos altos de la comunidad.

Palabras claves: Ciudad cerrada, Expansión urbana, fraccionamiento cerrado, ciudad abierta.

\section{Introducción.}

Las ciudades presentan una marcada tendencia a la expansión-densificación, pues cambia la lógica de los años setenta, cuando se concebía que el crecimiento de la ciudad consistía en su expansión física. ${ }^{2}$

Esta tendencia estimula el cambio morfológico de las ciudades, las dinámicas de descentralización serían identificables con los procesos de 'sprawl', a lo que se denomina "desparramiento urbano", lo que implica una mezcla de la ciudad central con los nuevos núcleos ocupados a su alrededor o contenidos en ella.

Encontrándose en una dinámica de desequilibrio urbano tendiente a construir y fomentar procesos caóticos de cambios rápidos ${ }^{3}$, fundamentándose esta dinámica en los nuevos estilos de vida en la zona periurbana de la ciudad, los cuales conforman nuevos desarrollos de tipo cerrado que actúan como subsistemas dentro de la ciudad, entre los que podemos mencionar comunidades cerradas, parques temáticos, centros comerciales, entre otros equipamientos que se integran en la urbanización por nuevas centralidades.

\footnotetext{
${ }^{1}$ Persona de contacto: Sylvia Cristina Rodríguez González, correo electrónico: sc sc802004@yahoo.com

2 "La ciudad ha tomado el camino del crecimiento a través de la transformación de lo existente" Amendola, Giandomenico La Ciudad Postmoderna: Magia y miedo de la metrópolis contemporánea. Madrid: Celeste ediciones, c2000, 1era. Edición, P.31. ISBN: 84-8211-239-2.

3 "El enfoque sobre las ciudades nos permite especificar una geografía de lugares estratégicos en la escala global, lugares ligados entre ellos por las dinámicas de la globalización económica" Sassen, Saskia. Los espectros de la globalización. Argentina: Fondo de Cultura Económica ediciones, c2003, 1era. Edición, P.16. ISBN: 950-557-5866.
} 
Estos nuevos desarrollos cuentan con el común de crear infraestructura en torno a ellos y conectarse con la ciudad abierta a través de vías rápidas, integrar otros equipamientos con nuevos núcleos que se extienden en los diversos sectores de la ciudad y propiciar la expansión urbana; de igual forma, fomentan la creación de equipamientos en su interior y generar procesos mercadotécnicos y problemas urbanos con la privatopia ${ }^{4}$, la especulación, la fragmentación, la segregación y la polarización.

\section{Antecedente.}

Es claro, que la participación de las urbanizaciones cerradas en la expansión urbana de las ciudades de Latinoamérica ${ }^{5}$, especialmente en las ciudades mexicanas, permite conocer las implicaciones del fenómeno, entre las que destacan problemas urbanos comunes en nuestras ciudades como segregación, inseguridad, especulación y privatización.

En el caso de México, los denominados fraccionamientos cerrados no solamente son una nueva forma de urbanización residencial, sino que forman parte de una transformación sociocultural más profunda. Los muros o rejas que se construyen son una metáfora de los procesos sociales que actúan en el paisaje social y político de las ciudades. Se trata de un debate que abarca temas complejos como los derechos y obligaciones privados versus los públicos; la colectividad ciudadana, la defensa de la calidad de la vida urbana; la fragmentación de la sociedad y la disolución del espacio público. ${ }^{6}$

La Primavera no constituye un fraccionamiento cerrado, en la actualidad es considerada el primer desarrollo municipal que da inicio a la conformación de una ciudad urbanizada de tipo cerrada, conectada con la ciudad abierta, a pesar de su amurallamiento que impacta con diversos problemas urbanos en los habitantes tanto de la ciudad abierta como de La Primavera.

Tradicionalmente las ciudades se conforman por asentamientos irregulares, que conforman comunidades basadas en una actividad económica que produce trabajo en un sector de un municipio, sin embargo es difícil la aceptación de crear una ciudad y cerrarla con la finalidad de otorgarle en su interior todo aquello que ha venido impactando a la ciudad abierta a problemas urbanos y aceptación de violencia. Por ello, se crea suelo urbano para la conformación de una comunidad con servicios de alto nivel, reglamentos que permitan fomentar en sus habitantes el respeto por el medio ambiente y con ello conformar una nueva sociedad sostenible, pero esto no es suficiente para la conformación de una ciudad por pequeña que sea su estructura.

\footnotetext{
4 “(...) en la ciudad nueva todo es presente y contemporáneo, puesto que ya no existen el pasado y la distancia. El resultado es un bien integrado sistema de fragmentos donde ya no hay presente y pasado, sino una serie de presentes de edades diferentes, todos autónomos pero interrelacionados en tanto están dirigidos a una misma audiencia fragmentada y cambiante" Amendola, Giandomenico. La Ciudad Postmoderna: Magia y miedo de la metrópolis contemporánea. Madrid: Celeste ediciones, c2000, 1era. Edición, P.78. ISBN: 84-8211-239-2.

${ }^{5}$ Janoschka, Michael. Nordelta: Ciudad Cerrada. El análisis de un nuevo estilo de vida en el gran Buenos Aires. Barcelona: V Coloquio Internacional de Geocrítica. Mayo 16-30, 2003, P.2. En: http://www.faudi.unc.edu.ar/mgdh/mutaciones/janoschka2003.doc

6 “...En México es de gran relevancia su presencia pues muestra la elección residencial de las élites urbanas en los ámbitos espaciales más valiosos respecto a accesos y condiciones paisajísticas y ambientales en el contexto de explosivas y precarias expansiones del área urbanizada de las ciudades. Su mayor desarrollo en los últimos años acontece y se explica dentro de las degradadas condiciones socio medioambientales de gran parte de las periferias de los núcleos centrales como de los ámbitos metropolitanos. Ambos procesos han afectado a la zona metropolitana de la ciudad de Toluca y de la ciudad de Puebla, creando sectores de gran calidad residencial y paisajística en un medio urbano infradotado y deficiente infraestructural y ambientalmente". Rodríguez Chumillas, Isabel y Ruiz-Gómez, Manuel Mollá. La vivienda en las urbanizaciones cerradas de Puebla y Toluca. Universidad de Barcelona: Revista electrónica de Geografía y Ciencias Sociales: Scripta Nova, Agosto 1, 2003, Vol. VII No 146, P.2. SIN: 1138-9788.
} 
Actualmente, La Primavera esta conformada por una sola clase social de nivel alto que no cubre sus necesidades en el interior del desarrollo, ya que las principales actividades de empresarios y políticos se llevan a cabo al exterior en la ciudad abierta.

El proyecto La Primavera surge con el eslogan de "ciudad rancho" y "ciudad verde", que hacen énfasis en sus grandes extensiones de área verde, así como también remarca elementos medio ambientales, que incluyen como ventaja un gran cuerpo de agua conocido como Dique La Primavera, que por su importancia está catalogado como aguas nacionales por el gobierno federal y que dentro del desarrollo habitacional, ha sido privatizado.

Durante los años noventa se promueve la expansión de Culiacán a través de planes sectoriales, cuya implementación propicia la creación del suelo urbano en el que se asienta el megaproyecto periférico, autorizado como una Zona Especial de Desarrollo Controlado (ZEDEC), ya que contaba con áreas de reserva agrícola.

Los antecedentes inmediatos y locales del diseño urbano de La Primavera se ubican en Culiacán, en el fraccionamiento cerrado Los Álamos. Éste, basado en principios del nuevo urbanismo, privilegia el medio ambiente y la vida comunitaria, con una administración que les permite conservarlo en las mejores condiciones. Con el mismo propósito se crea La Primavera, siguiendo seis reglas de principios híbridos ${ }^{7}$ : el primero indica que la seguridad para sus habitantes corresponde al un desarrollo amurallado totalmente, con vigilancia propia; el segundo estipula un alto porcentaje de áreas verdes y amplísimas áreas libres por habitante; el tercero corresponde al usufructo de un lago de 269 hectáreas, casi único en el urbanismo mexicano; el cuarto es la imagen urbana controlada por un reglamento interno; el quinto es la vocación ecológica del proyecto, demostrada de antemano en el tratamiento dado al dique, a los arroyos, al cuidado de la flora existente y al programa de arborización que lleva un volumen de plantación cercano a los 30 mil árboles, y el último es la posibilidad de vincular el trabajo con la vivienda y los servicios, según el modelo de las ciudades satélites y de las new towns inglesas, al contar con una zona industrial.

Figura 1 Plano del sector La Primavera al sur de la ciudad de Culiacán (polígono de color café; la franja azul adyacente es el dique).

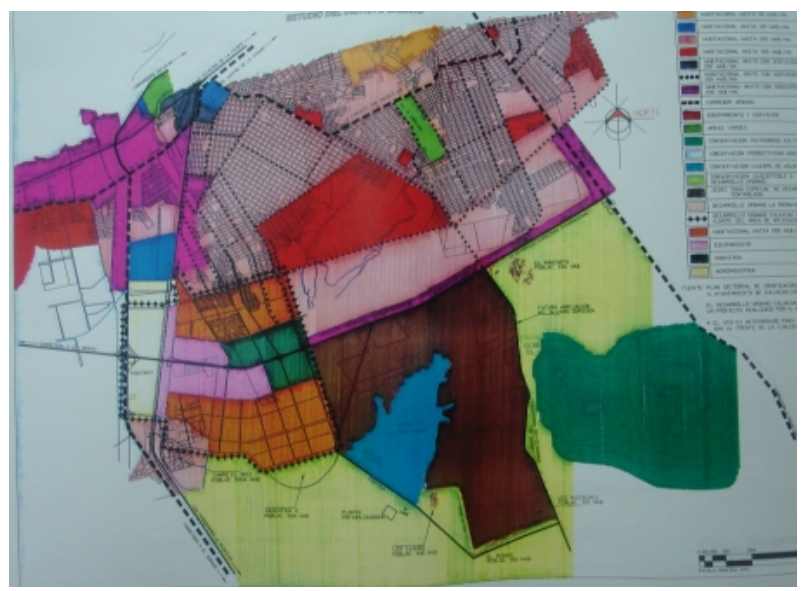

Fuente: H. Ayuntamiento de Culiacán. "Aprobación de fraccionamientos". Actas de cabildo municipal de 1970 al 2005; Plan Sectorial de Zonificación de usos de suelo actualización 2004.

\footnotetext{
${ }^{7}$ Traducido del Charter of the New Urbanism, aprobado por El Congreso para el Nuevo Urbanismo. Carta del Nuevo Urbanismo. Consultado el 20 de Novimbre de 2005. En: http://www.cnu.org/pdf/Carta espanol.pdf
} 
El Plan Parcial de Desarrollo Urbano La Primavera inicia su creación con 819.92 hectáreas, con la pretensión de ofertar suelo para nuevos usos: habitacional, de servicios, industrial, áreas verdes, infraestructura y equipamiento, además de precisiones particulares en torno a usos educativo, cultural y turístico, como se visualiza en la figura 1 y el Plano de Zonificación de usos del suelo de 1996, justo antes de la publicación de la reforma de ley agraria. Las propuestas se justifican con la necesidad de crear enlaces peatonales, vehiculares y navegables, así como para integrar armónicamente las actividades a desarrollar y mejorar la calidad del medio ambiente con la reforestación, rescate y mantenimiento del lago, canales y arroyos. Todo esto, de acuerdo al Plan Parcial, con la finalidad de hacer del nuevo desarrollo un punto turístico atractivo a las inversiones que fortalezcan la economía regional gracias a la construcción de un modelo de desarrollo urbano que supone fortalecería los valores humanos ${ }^{8}$.

En busca de un nuevo estilo de vida que alude a los principios del nuevo urbanismo, en La PrimaVera se planea la conservación y crecimiento de la fauna y la flora existentes, a la vez que el mayor control y seguridad se logrará mediante una barda perimetral combinada con el dique para el riego agrícola -ahora lago para el ocio- y el canal San Lorenzo que le surte de agua ribereña. Se propone consolidar los espacios verdes preexistentes en el área, acompañados ahora del "mantenimiento integral" que incrementaría la identidad, prometiendo aumentar significativamente la calidad de vida local en virtud de la dotación de nuevos jardines, servicios comunitarios, escuelas funcionales, parques y espacios recreativos. ${ }^{9}$

La pretensión inicial del proyecto es crear de una comunidad basada en la "armonía", la seguridad y el contacto con la naturaleza, integrando áreas para vivienda, comercios, iglesia, zona hotelera, escuelas, áreas deportivas y recreativas con la inclusión de un campo de golf, oficinas, hospitales, universidad y parque industrial. Se intenta, pues, incorporar todas las actividades propias de una ciudad en la acepción neourbanística norteamericana. Congruentemente, el programa arquitectónico preliminar constaba de las siguientes áreas y etapas: 1) plaza de la iglesia; 2) centro comercial; 3) "barrios" San Agustín, San Luis, Isla del Oeste, Zona Comercial, Isla del Este y San Anselmo; 4) campo de golf; 5) parque industrial, y 6) dique La Primavera. Se propone en este primer concepto albergar una población de 55,000 habitantes, de acuerdo a las características del predio y a los ingresos de los vecinos potenciales, se establecen áreas de densidad variable: a) especial (50 hab/ha) y tamaño promedio del lote de $600 \mathrm{~m} 2$; b) baja (80 hab/ha) y tamaño promedio del lote de $600 \mathrm{~m} 2 \mathrm{c}$ ) media (110 hab/ha) y tamaño del lote en promedio de $450 \mathrm{~m} 2$.; d) alta (200 hab./ha.) y tamaño del lote en promedio de $450 \mathrm{~m} 2$, y e) máxima (300 hab./ha.) y tamaño promedio del lote de 450 $\mathrm{m} 2^{10}$.

\footnotetext{
8 "En La Primavera los valores humanos se desarrollan en plenitud, armonía y paz con la naturaleza". KYARA, S.A. DE C.V. "Folleto promocional La PrimaVera". Culiacán, Sinaloa, México.

9 "El referente es creado por los promotores según las imágenes difundidas con la propaganda revisada por los especialistas y que he corroborado en ciudades mexicanas. Pero está sobre todo anclado en el manejo simbólico del lenguaje del diseño urbano y arquitectónico, generando tipologías funcionales y formales de concepción historicista, cuya sola asociación con la experiencia estadounidense le da un plus comercial". Méndez Sáinz, Eloy. "Vecindarios defensivos latinoamericanos. Los espacios prohibitorios de la Globalización. Revista Perspectivas Urbanas / Urban perspectives. No 4. P.15. Consultado el 1 de enero de 2005 . Disponible en: https://erevistes.upc.edu/bitstream/2099/584/2/art04-2.pdf
}

\footnotetext{
10 "La PrimaVera es un ejemplo práctico, concreto, que demuestra el resultado de una planeación adecuada, Culiacán, debería de copiar lo bueno, demostrado, y además va a hacer más atractivo vivir en Culiacán en La PrimaVera". Desarrollos como La Primavera se consideran por un sector de la sociedad como una alternativa de crecimiento "porque se vive mucho mejor, más barato, hay más plusvalía, etc.", bajo el concepto de "ARMONIA, se logra una planeación correcta, aprovechando las características del lugar, su orografía, vistas, vientos, temperaturas, etc." Asimismo es destacable que La Primavera aporta innovaciones a la ciudad como: "Vías rápidas; vialidad peatonal; arroyos naturales formando parques lineales, verdes, con andador, sombreados; los principales destinos con acceso directo al agua, la ubicación correcta de cada futuro local de acuerdo al uso, ya programada; el lago, los canales, islas,
} 
En la concepción actual, la que está en proceso de implementación, el conjunto es un polígono de 819.82 hectáreas, rodea al lago y tiene accesos que la conectan directamente a vialidades primarias regionales. El desarrollo urbano La Primavera es un banco de suelo urbano con elementos naturales para promoverse como "ciudad verde", "ciudad ambiental", "ciudad de calidad" o "ciudad para generaciones futuras".

Tabla 1 Mezclas de usos del suelo

\begin{tabular}{|l|l|l|}
\hline Usos de Suelo & Superficie de polígono $\mathbf{( H a )}$ & $\%$ \\
\hline Habitacional & 397.83 & 48.53 \\
\hline Industria & 128.33 & 15.65 \\
\hline Área verde & 178.56 & 21.78 \\
\hline Vialidad & 115.10 & 14.04 \\
\hline Total & 819.82 & 100.00 \\
\hline
\end{tabular}

Fuente: H. Congreso del Estado libre y Soberano de Sinaloa, H. Congreso del Estado libre y Soberano de Sinaloa. "Plan Parcial de Desarrollo Urbano La Primavera". En el Periódico Oficial "El Estado de Sinaloa" México: Gobierno del Estado de Sinaloa (c1998), No150, P.2.

En entrevista con uno de los propietarios de La Primavera, se confirmaron usos generadores de una ciudad satélite, una nueva centralidad en la ciudad abierta, él señalaba que La Primavera tendrá todo lo que una ciudad necesita y más, porque se motiva a sus habitantes a través de reglamentos interiores a cumplir con el cuidado y respeto por la naturaleza; asimismo comento, que sobre los muros, el considera que son necesarios, que no existiría La Primavera si estos no estuvieran, fuera muy diferente, porque tendrían diferentes tipos de delitos, tal vez en las vialidades y andadores al ser amplios y armoniosos tendrían ambulantes y perdería su esencia.

Por ello, el plan maestro contempla desarrollar 7,957 lotes en total, con $500 \mathrm{~m} 2$ por lote promedio, densidad de 12 lotes y 24 viviendas por hectárea. Se planea consolidar el megadesarrollo en un plazo de 25 a 30 años a partir de fecha de creación, y se prevé que para el año 2011 se encontrará densificado en su mayoría. La lotificación del desarrollo se distingue en función de la cercanía con el lago, los privilegiados están frente al manto acuífero y los menos cotizados son los más alejados del mismo. La actividad industrial en el nuevo núcleo es uno de los ejes centrales, ya que el proyecto inicial indica que el $24 \%$ del suelo será ocupado por este uso como se indica en la tabla 1, a lo que denomina la empresa diseñadora "un megadesarrollo creado con una visión integral."

La Primavera puede ser considerada como ciudad cerrada ya que cuenta con un sustento legal

el uso y aprovechamiento correctos. Remo, pesca, esquí, vela, waverunners, nado, y una red acuática que permite visitar los principales destinos por agua; plantar los árboles correctos antes de fraccionar; respeto a las colinas y curvas de nivel natural; planeación a muy largo plazo, zonas para casas ahora, pero edificios de 20 pisos dentro de unos años después, bien ubicados; todos los servicios ocultos de alta calidad y muy bajo costo (agua potable, agua de riego filtrada, drenaje, electricidad en alta y baja tensión, cablevisión, telefonía, avanzada, gas, iluminación, etc); una ciudad de calidad muy alta para gente de nivel medio, que en otras ciudades, no podría pagar; área industrial, comercial, deportiva, educativa, diversión, todo dentro de la ciudad; estilos arquitectónicos armónicos por barrio; casas, clubes deportivos en todos los barrios (mucho enfoque al deporte y la educación); alta seguridad con poca afectación al usuario y habitante y selección de condóminos (no aceptar a familias dedicadas a actividades ilícitas, como el tráfico de drogas, etc.)". Enrique Coppel Luken: Socio de La Primavera (2006) "Entrevista", Culiacán, Sinaloa, México: Oficinas Coppel, Junio 19, 2006 (documental y sin grabación), 17:00-17:30 hrs. 
que le permite sentar las bases para continuar con su expansión y fundamentación como tal, ya que es el único desarrollo en la ciudad y a nivel estatal que cuenta con usos que la distinguen de cualquier fraccionamiento cerrado, los giros de usos del suelo son diversos en el interior del desarrollo, cuenta principalmente con barrios cuya función es la habitacional, sin embargo, cuenta con grandes extensiones de áreas verdes destinadas al esparcimiento, un porcentaje semejante en vialidades, aguas nacionales en su interior, usos desde el comercial y educativo hasta el religioso.

\section{La Primavera}

\subsection{Proceso de expansión urbana}

Suelo rural por suelo urbano. Las transferencias del suelo, son una de las principales razones de esta gran inversión, el valor del suelo ha cambiado y a ejercido su nuevo valor al interior. La transformación legal del suelo a urbano, sigue un proceso aparentemente sencillo de tres términos, una triangulación que parece increíblemente sencilla pero que llevo casi cien años después de la revolución. La gestión política y administrativa se ve reflejada en la reforma de la ley agraria en el artículo 27, donde se permite la autorización de concesiones sobre la tierra, es decir cada uno de los ejidatarios obtiene una responsabilidad sobre su sección ejidal, los gobiernos se triangulan. El proceso inicia de la transformación federal a estatal, es decir un suelo agrícola o ejidal se convierte a suelo rural, es decir del estado, donde el poder estatal puede ejercer usos sobre el suelo bajo específicos objetivos uno de ellos es en el que se fundamenta un desarrollo como La Primavera el uso para el bienestar de la ciudad a partir de un proyecto urbano detonante en el Municipio y en el Estado, sin embargo para convertirlo en suelo urbano y poder ejercer la autorización para construcción sobre el suelo se requiere que este sea autorizado por el gobierno municipal como suelo urbano. Es decir a partir de este cambio la ciudad de Culiacán se extendió casi mil hectáreas en proyecto.

Figura 2 Área urbana del sector sur de la ciudad de Culiacán Rosales al 2005

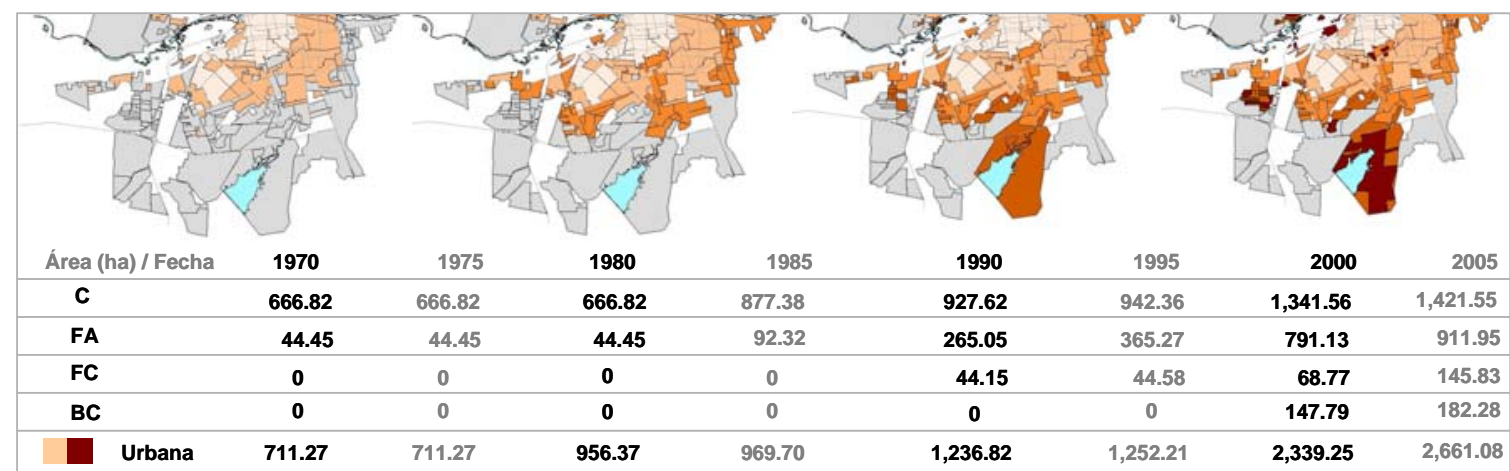

Aguas nacionales

(C) Colonias, (FA) Fraccionamientos Abiertos, (FC) Fraccionamientos Cerrados (BC) Barrios Cerrados

Culiacán, Sinaloa, México: Cabildo del H. Ayuntamiento, 1970 al 2005.

Actualmente, el área urbana del sector sur se ve influenciada en su mayoría por colonias populares, con incremento de fraccionamientos cerrados y barrios cerrados en la última década, como se indica en la figura 2.

Es considerable señalar que el entorno en la zona sur del desarrollo La Primavera se mantiene rodeado de suelo rural, es decir zonas que aunque no son productoras activas como 
ejidales o agrícolas si están destinadas para un uso que no es considerado urbano, actualmente en la zona norte el desarrollo urbano ha permitido la expansión de la ciudad principalmente por otros fraccionamientos que son separados por el Libramiento Benito Juárez, ya que dicha carretera se encuentra bajo poder gubernamental federal hasta la fecha.

Las tierras fueron adquiridas por el desarrollo, ejidos El Quince, Las Flores, Huizaches, El Vallado, El Ranchito y Los Llanos, a través del programa PROCEDE de la Secretaría de la Reforma Agraria y que coordinan la Procuraduría Agraria, INEGI y El Registro Agrario Nacional. Esto permite al ejidatario regularizar y tener un certificado parcelario.

Actualmente se tiene el dominio pleno a través de títulos de propiedad debidamente legalizados.

Los principales objetivos en la Primavera son:

- Hacer factible la oferta de suelo destinada a usos habitacionales, educativos, culturales, recreativos, turísticos e industriales, en los que su comercialización posibilite la realización de las obras que se requieran.

- Enlazar en forma equilibrada todos los puntos del desarrollo mediante vialidades peatonales, vehiculares y navegables.

- Integrar en forma armónica las actividades de vivienda, educación, deporte, recreación y trabajo.

- Mejorar la calidad del medio ambiente con la reforestación y el rescate y mantenimiento del lago, canales y arroyos.

- Hacer el Desarrollo un punto turístico.

- Atraer inversiones que fortalezcan la economía de Culiacán y del Estado.

- Construir un modelo de desarrollo urbano ${ }^{11}$.

Coeficientes de aprovechamiento únicos. El desarrollo urbano La Primavera cuenta con diversos coeficientes de aprovechamiento, pero creo importante mencionar dos que actualmente lo señalan como el único y el más grande desarrollo urbano de este tipo en el estado, en el país y posiblemente a nivel internacional.

El primer desarrollo urbano cerrado de nivel nacional que cuenta con un dique en su interior, mismo que forma parte del sistema de los ocho diques del estado de Sinaloa y cuenta con su concesión por cincuenta años, así mismo el primer desarrollo urbano cerrado conceptualizado como un modelo de desarrollo urbano capitalista chino, ya que es el único que se conoce con estas dimensiones que cuenta con un área industrial destinada a la fabricación de textiles chinos en su interior.

Es decir podemos encuadrar al desarrollo urbano La Primavera como una prima potencia internacional como desarrollo que ejerza la privatización del espacio público, dos elementos primordiales para la competitividad de las ciudades de nivel mundial, el recurso natural privilegiado de tipo no renovable; el agua a partir del dique La Primavera y una permisión de establecer una zona industrial dentro de un desarrollo habitacional, que hasta el momento se

\footnotetext{
${ }^{11}$ Congreso del Estado de Sinaloa "Ley de desarrollo urbano del estado de Sinaloa", Septiembre 1, 2004, decreto No659, P.O. №105, Cap.4, Sección II.
} 
encuentra legalmente sustentada, por ello se indica como una permisión, ya que es establecido por la Organización de la Nacionales Unidas que las zonas industriales de primer grado deben encontrarse fuera de zonas habitacionales para evitar convertirse en una zona de riesgo, es conocido por nosotros que el planteamiento del desarrollo es basado en el concepto de bienestar en su interior, con elementos arquitectónicos que permitan elevar la calidad de vida en su interior y que el área industrial se posiciona dentro del desarrollo bajo el concepto de los club system en china, establecer un sistema de comunicación entre la actividad económica principal de los habitantes del desarrollo, es decir una pequeña ciudad inmersa en la gran ciudad.

Concesiones. La Primavera, esta basada en permisiones como en concesiones. Las permisiones representativas del desarrollo son variadas, pero es importante destacar uno de las principales que da origen al modelo de desarrollo urbano planteado para La Primavera a partir de un convenio de promoción y desarrollo económico firmado a finales de los años noventas por Gobierno del Estado de Sinaloa, el H. Ayuntamiento de Culiacán y la Empresa Tex Ray Industrial Co. LTD con filial mexicana Tex-Ray México, S.A. de C.V. en la ciudad de Culiacán, con el objetivo de instalar en el estado de Sinaloa dos plantas industriales: una para el teñido de telas y la otra para tejer, las cuales producirán entre 300 mil a 600 mil kilogramos mensuales y generarán de 200 a 250 empleos, con una inversión de 9 a 11 millones de dólares USD, en un plazo no mayor de 24 meses. Donde se proponía que en el futuro se podrá crear una fábrica de ropa que generará aproximadamente 2,000 empleos, proyecto que de hacerse realidad requerirá de la suscripción de un nuevo convenio. Comprometiéndose la empresa a invertir 9 a 11 millones de dólares en la instalación de dos plantas industriales para teñir y tejer telas, en un plazo no mayor de 24 meses contados a partir de la firma del convenio; las cuales producirán entre 300 mil a 600 mil kilogramos por mes.

Es importante remarcar que el uso destinado para industria dentro del desarrollo originaba un consumo de aguas mexicanas y el origen de desechos industriales de primer grado como lo indicó la Comisión Nacional del Agua. Por lo cual se estableció en el convenio el tratamiento a las aguas residuales de conformidad con lo dispuesto en las leyes de la materia.

El consumo de agua para industria a partir del comodato establecido a favor de La Primavera durante el año dos mil tres, impide que lo establecido por JAPAC en un inicio con la construcción del nuevo tanque para cubrir poblaciones aledañas no se llevará a cabo y se requiriera mayor inversión para cubrir los fraccionamientos originados en los últimos cinco años por ejemplo, lo cual ha tenido que ser cubierto por el gobierno municipal en algunos sectores, no todos han sido cubiertos como el fraccionamiento del proyecto alfa de servicios progresivos, actualmente dichos no existen los servicios, a pesar de estar fundamentado en programas federales.

Al no encontrarse planeada integralmente la ciudad la expansión urbana es diferencial al dispararse sin equidad, ocasionando segregación urbana ya que pueden existir fraccionamientos con todos los servicios y otros sin ninguno en un mismo entorno.

Las concesiones en el desarrollo urbano La Primavera, sobresalen dos: la primera corresponde al permiso de constituirse como un desarrollo cerrado, bajo la concesión de la ley de condominios del estado de Sinaloa. Y la segunda concesión es la de aguas nacionales, el dique La Primavera. 
A mediados del año dos mil cuatro, la comisión Nacional del Agua ${ }^{12}$ otorgó el Título de Concesión a la empresa denominada KYARA, S.A. de C.V., toda vez que cumplió con las disposiciones y requisitos establecidos por la Ley de Aguas Nacionales y su Reglamento, concediendo con ello el derecho para explotar, usar o aprovechar aguas nacionales superficiales por un volumen de 5,957,676.00 metros cúbicos anuales, por un plazo de cincuenta años prorrogables contados a partir de la autorización, teniendo como fuente de abastecimiento el canal principal San Lorenzo y un uso clasificado como público urbano, en virtud de destinarse para abastecimiento de agua potable ${ }^{13}$.

Así mismo durante el mismo año 2004 se concesiona a La Primavera el servicio público de agua potable y alcantarillado exclusivamente dentro del desarrollo urbano por un plazo de cincuenta años prorrogables ${ }^{14}$. La última concesión publicada en septiembre del año pasado, se concesionan aguas nacionales para uso público urbano dentro del desarrollo urbano.

\subsection{Los barrios cerrados en La Primavera}

Después de 7 años de iniciado el proyecto, el complejo urbano está constituido por el área habitacional de los "barrios" Isla del Oeste, San Agustín, San Luis, Isla del Este y San Anselmo, un área industrial, áreas verdes que incluyen campo de golf profesional, equipamiento integrado por la plaza de la iglesia, el centro comercial y el barrio zona comercial, vialidades y en un gran porcentaje de "área azul" integrada por el lago principalmente.

El parque industrial es promovido por los inversionistas del proyecto en el ámbito internacional, proyectado por la empresa AXYA, S.A. de C.V. ${ }^{15}$ Su diseño ofrece espacios como centros especializados de distribución y logística, textil, plásticos, manufacturera y metal-mecánica. Se planea que cuente con telecomunicaciones de fibra óptica y cobre, redes separadas de descargas de aguas residuales industriales y domésticas, seguridad interna las 24 horas del día, apoyada con una barda perimetral de 4 metros de altura de concreto armado, parques públicos con zonas deportivas y vialidades funcionales. Cuenta con 71 hectáreas adyacentes al lago artificial con un espejo de 272 hectáreas; se han reservado espacios para oficinas corporativas y de servicios junto a los lotes industriales, con la mejor infraestructura de Culiacán.

El "barrio" industrial de La Primavera tiene como objetivo instalar dos plantas industriales, una para el teñido de telas y la otra para tejer, las cuales producirán entre 300 mil a 600 mil kilogramos mensuales y generarán de 200 a 250 empleos, con una inversión de 9 a 11 millones de dólares en un plazo no mayor a 24 meses. En el futuro se creará una fábrica de ropa que generará aproximadamente 2,000 empleos.

\footnotetext{
${ }^{12}$ Comisión Nacional del Agua. "Comunicado de inicio de procedimientos de determinación de faltas e imposición de sanciones a la empresa KYARA, S.A. de C.V.". Expediente No. VI-PNI-2002-III-007, Oficio No.BOO.00.R04.040679/3443. Culiacán, Sinaloa, México: Gerencia Regional Pacífico Norte, Subgerencia de Administración del Agua, Agosto 20,2002 .

${ }^{13} \mathrm{H}$. Ayuntamiento de Culiacán. "Solicitud para concesión de uso público urbano de aguas nacionales dentro del desarrollo urbano La Primavera". En el Oficio S/N. Culiacán, Sinaloa, México: Secretaria del H. Ayuntamiento, septiembre 23, 2003.

${ }^{14}$ Gerente General JAPAC. "Contratos adicionales al de prestación de servicios, comodato por el uso gratuito y temporal de la Planta Potabilizadora y el otro por prestación de servicios con la empresa filial"

15 "La zona industrial se proyecta desde los inicios de proyecto por la empresa AXYA, S.A. de C.V., ya que se requería de una zonificación destinada para sustentar la inversión del desarrollo". Crónica del Municipio de Culiacán. "Expediente Desarrollo Urbano La Primavera". AXYA, S.A. de C.V. Acta 60, Punto VI: a. Culiacán, Sinaloa. Octubre 1997.
} 
Para barrio Isla del Oeste se propone en una densidad de seis habitantes por lote, previendo tener una población de 900 habitantes, ocupa 118,773.55 m2 que incluyen 150 lotes. El barrio San Luis se ubica sobre el terreno delimitado por la vialidad Javier Calvo y un canal acondicionado para verter el agua de arroyos en el lago ${ }^{16}$, se trata de otorgar mejores servicios, seguridad y desarrollo social en marco de respeto entre los habitantes y su entorno natural. Con una densidad de seis habitantes por lote, el barrio tiene una población de 954 habitantes, ocupando una superficie de 177,577.35 m2.

El área de restricción corresponde a un estatus establecido en el reglamento interior del barrio, donde establece que al frente de todo tipo de lote se tendrá una restricción de cinco metros y en su parte posterior será de tres metros, la lateral será de dos metros.

El barrio San Agustín se ubica sobre el terreno delimitado por la Vía Calvo, la barda perimetral y un canal acondicionado para verter el agua de los arroyos en el lago La Primavera ${ }^{17}$. Basándose en una densidad de seis habitantes por lote, se conforma por una superficie de $297,943.658 \mathrm{~m} 2$ distribuido principalmente en 442 lotes. El área de restricción corresponde a un estatus establecido en el reglamento interior del barrio San Agustín, estableciendo que al frente de todo tipo de lote se tendrá una restricción de $5.00 \mathrm{~m}$. y en su parte posterior será de $3.00 \mathrm{~m}$., lateral será de $1.50 \mathrm{~m}$.

En el barrio Isla del Oeste se encuentra el área de la isla abarcando el $46 \%$ y los canales el $7 \%$, así mismo se reconoce que un poco más del 50\% se privilegia al área azul dentro de este barrio. El barrio San Luis cuenta con el área de canal al oriente, con una extensión de 23.70 hasta $30.00 \mathrm{~m}$., de 2.50 hasta $8.00 \mathrm{~m}$. de lecho y con una profundidad de $4.40 \mathrm{~m}$. Se propone integrar el canal dentro de una red acuática navegable interna del desarrollo, con una extensión de $1 \mathrm{~km}$. El barrio San Agustín cuenta con el área de canal al oriente, con una extensión de 23.70 hasta $30.00 \mathrm{~m}$., de 2.50 hasta $8.00 \mathrm{~m}$. de lecho y con una profundidad de $4.40 \mathrm{~m}$. Se propone que el canal San Luis rodee la parte extrema al sur, los arroyos cuenten con una extensión de 1,919.28 m. con áreas de jardín de $6.00 \mathrm{~m}$. en promedio, conformar parques lineales, con una extensión de $1 \mathrm{~km}$. El barrio zona comercial, cuenta con un área de canal al oriente, con una extensión de 23.70 hasta $30.00 \mathrm{~m}$., de 2.50 hasta $8.00 \mathrm{~m}$. de lecho y con una profundidad de $4.40 \mathrm{~m}$. Se propone que el gran canal y el canal San Luis al bordear la parte sur, sean navegables ya que cuenta con áreas verdes y andadores que se enlacen entre lotes con una extensión de $1 \mathrm{~km}$.

Los barrios que cuentan con área verde y de tipo recreativo son las zonas habitacionales y comercial. El barrio Isla del Oeste, representa el $72 \%$ de área verde y recreativa, entre el área que incluye la isla y el canal, casa club y áreas de jardín. El barrio San Agustín, representa el $20 \%$ del total con especies como palma, olivo negro, orquídea amapa, guanacaxtle, almendro y saman. El uso que se propone para el área de andadores, es de uso peatonal y para deportistas incluyendo la equitación, con un ancho promedio de $4.00 \mathrm{~m}$. El barrio San Agustín, representa el $16.38 \%$ del total con especies como vinolo, vara blanca y malva. El uso que se propone para el área de andadores, es de uso peatonal y para deportistas incluyendo la equitación, con un ancho promedio de 2.60 y $6.00 \mathrm{~m}$.

\footnotetext{
16 "Se realizan memorias descriptivas y cuentan con un expediente que sustenta la aprobación del barrio". KYARA, S.A. DE C.V. "Memoria descriptiva San Luis, La Primavera". Expediente San Luis, La Primavera: Archivo Municipal de Culiacán, Sinaloa, México. PP.1-44.

17 "Cada una de las secciones denominadas barrios continúan describiendo el proyecto por medidas específicas ya que son establecidas igualmente para su cumplimiento en un reglamento interno del barrio". KYARA, S.A. DE C.V. "Memoria descriptiva San Agustín, La Primavera". Expediente San Agustín, La Primavera: Archivo Municipal de Culiacán, Sinaloa, México. PP.1-18.
} 


\subsubsection{Modelos Arquitectónicos en vivienda}

Figura 3 Vista panorámica de La Primavera

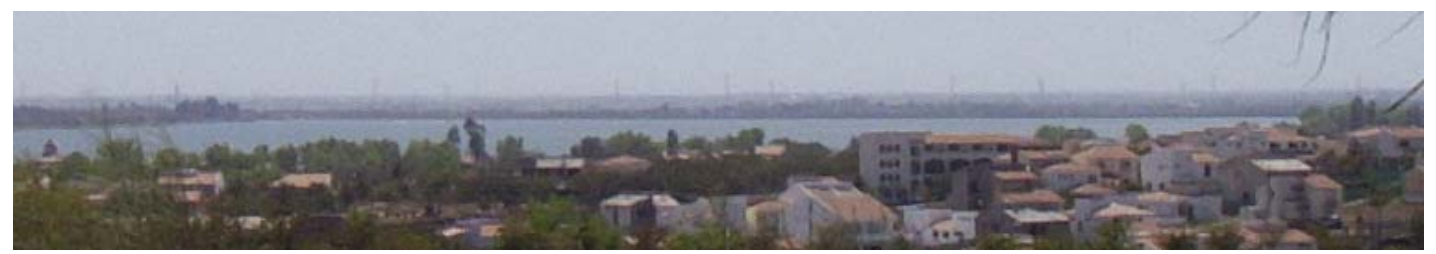

ruente: Propıa.

Como se visualiza en la figura 3, la mayoría del equipamiento urbano del proyecto La Primavera, esta constituido por viviendas, las cuales basan en cincuenta modelos de viviendas ${ }^{18}$, desde 95 hasta 600 metros cuadrados de construcción; la empresa encargada de dichos proyectos arquitectónicos es la constructora MegaPark, S.A. de C.V., misma que se justifica como una empresa que busca construir a un precio menor que la construcción tradicional, de forma ordenada, rápida, eficiente, sin errores, sin desperdicios y con alta calidad, sobretodo menciona que diseñan casas que gusten y se adapten a cada uno de los clientes, mediante un estudio de necesidades a fondo para lograr gran eficiencia y economía del proyecto. Los modelos de casas diseñadas para terrenos en barrios de La Primavera son cincuenta, desde $95 \mathrm{~m} 2$ hasta $600 \mathrm{~m} 2$ de construcción.

Los modelos de mayor demanda en La Primavera son de 200 a 300 metros cuadrados (m2) de construcción con un precio de $\$ 6,550 \mathrm{~m} 2$ de construcción para acabados estándar; lo cual consiste en aire acondicionado integral (aparato y ductería), cocina integral, pisos de cerámica, paredes y techos super-aislamiento, ventanas de aluminio con vidrio doble, muebles, llaves y accesorios de baño, closets en todas las recámaras, canceles de aluminio en todos los baños, contratos de luz, agua y gas, tanque de gas, fumigación contra termitas, respaldo de panel rey en el cálculo estructural, puertas interiores, exteriores y principal, calentador de agua, lavadero, diseño de la casa a su medida, gusto y necesidad (Arquitecto personal). Asimismo, las casas construidas con este tipo de acabados tienen la opción de adicionar de manera opcional otros acabados, que se cotizan en presupuesto, como la instalación de abanicos de techo, filtro de agua, tinaco, aljibe, hidroneumático, lavadora, secadora, estufa, horno, microondas, triturador de desperdicios, lavavajillas, refrigerador, cortinas, persianas, lámparas, muebles empotrados, nichos, plafones especiales, luces indirectas, alberca, jacuzzi, cablevisión, sonido, interfón, teléfonos, alarma, Internet, red inalámbrica, sistema de riego, portón de cochera, domos, etc. A pesar de toda esta serie de prestaciones que ofrece el programa arquitectónico para la vivienda en La Primavera, se aclara que el contrato no incluye ningún tipo de obras exteriores como bardas, jardines, rejas, etc. y que la empresa puede prestar dichos servicios, siendo estos los más importantes en el concepto de La Primavera como Ciudad Verde.

\footnotetext{
18 "Modelos arquitectónicos construidos en La Primavera: Gardenia (95 m2), Tipo T (100 m2), Yuca (104 m2), Cameron (114 m2), Laurel (120 m2), Arizona LP (130 M2), Roble (135 m2), Arcadia (136 m2), Bakerville (166 m2), Arcadia 2 y Arcadia (176 m2), Boston T1 y T2 (181 m2), Arcadis (183 m2), Boston Cristi (186 m2), Florida (200 m2), Girasol (206 $\mathrm{m} 2)$, California (216 m2), California (222 m2), California (227 m2), California, Nevada 1, 2 y 3 (232 m2), Perla (250 m2), Luz (253 m2), Diamante (254 m2), Cantera (261 m2), Muro (263 m2), Montana (264 m2), Paz (277 m2), Nova, Turquesa (280 m2), de la Colina, Carmin (295 m2), Greca (296 m2), Rubí (300 m2), Ventana y Alba (312 m2), Esmeralda (320 m2), Zafiro y Torre (329 m2), Faro (342 m2), Ticul (351 m2), Nevada 4 (364 m2), Palmares (370 m2), Granada (373 m2), Topacio (377 m2), Arco (378 m2), Los Lagos (405 m2), Gema (418 m2), Peach (420 m2), Matisse (431 m2) y Jade (600 m2)". Constructora MegaPark, en: www.megapark.com.mx
} 


\subsubsection{Elementos urbanos al interior de La Primavera}

La Primavera para considerarse una Ciudad Cerrada, además de incluir diversos usos en su interior ha tenido que intervenir y ser intervenida por una serie de manifestaciones urbanas de gran impacto. Algunas de estas manifestaciones destacables son al interior exclusividad, seguridad y autosegregación.

La Primavera es el desarrollo cerrado más grande de la ciudad de Culiacán y su impacto es tal como el de una ciudad pequeña, asimismo, sus manifestaciones al exterior son altas sobre todo con lo que respecta a las personas que habitan, trabajan y visitan el desarrollo, ya que la seguridad es uno de los elementos más destacables de sus manifestaciones.

Actualmente el desarrollo cumple con la manifestación de exclusividad, delimitando sus barrios con murallas a su interior con ello demarcando el estatus socio económico de los grupos que habitan el desarrollo. Elementos urbanos como amplios andadores y vialidades, la incorporación de canales de comunicación, amplias áreas verdes, el destinar gran espacio del desarrollo a la recreación a través de un club desde la tradicional y conservadora piscina hasta el club náutico desarrollado en el dique La Primavera, todo ello como elementos únicos en la ciudad para uso común lo que les permite una exclusividad única hasta el punto de autosegregarse, al mantener una concentración de usos que prefieren no hacer contacto con el exterior ya que opinan que al interior cumplen mejor con la adquisición de espacios para el ocio y recreación, mismo que les permite mantener el contacto directo con otros socios del desarrollo que generalmente comparten sus mismos interés, entre los que destacan de tipo económicos.

La Primavera cuenta con sistemas de seguridad desde el control del acceso por caseta de vigilancia controlada y personal de seguridad privada en el interior del desarrollo en vehículos para su desplazamiento en el desarrollo, sistema de alarma y electrificación alrededor de su barda de concreto armado en bloques de separación de 3.50 divididos en bloques en su altura de 2.00 de 4.00 metros de altura más el cableado en la parte superior del muro. Lo destacable del sistema de seguridad privado con el que cuenta el desarrollo es un sistema de telecomunicaciones con su propia antena de control de comunicaciones ubicada en la parte frontal del desarrollo en el extremo hacia la autopista, lo más cercano a la ciudad abierta, aunque es destacable mencionar que la altura de la antena en proporción con las antenas de telecomunicaciones que cubren a la ciudad con una altura aproximada de 40 metros de altura.

Pero la seguridad es una de las manifestaciones más demandadas en toda la ciudad, es uno de los privilegios que presumen al interior los habitantes del desarrollo, sin embargo es importante destacar que las murallas son un monumento a esta simulación, ya que bajo una lógica de reforzar la vigilancia al interior con un sistema integral de seguridad La Primavera ofrece mejor seguridad que en el exterior en cuando a problemas urbanos como robos, asaltos y violaciones. Pero es destacable manifestar que la inseguridad se manifiesta diferente, ya que las condiciones sociales se dirigen a otro rango de violencia.

Esta misma seguridad hace sentir a sus habitantes con cierta privacidad en su interior, a partir de las barreras y las diversas áreas verdes y recreativas en su interior proporcionan aislamiento de la realidad de la ciudad abierta. Sin embargo, entorno al desarrollo se aprecia gran segregación social, los niveles socioeconómicos entorno son marginales en lo que corresponde en el área rural, frente al desarrollo se fragmenta la ciudad a través de enclaves de colonias progresivas, donde las barreras son fraccionamientos de interés social con vista a las vialidades de contacto con el desarrollo, se crean nuevos usos de suelo sobretodo de tipo comercial, desde supermercados hasta plazas. 
La especulación sobre el suelo propicia su transformación y elevación de su plusvalía, por ello se generan equipamientos que cubren servicios y necesidades básicas en el entorno, pero a su vez propicia la disminución de oportunidades para los más desprotegidos de obtener suelo apto para una adquisición de una vivienda.

\section{Sector sur entorno La Primavera}

La ciudad de Culiacán a principios de los noventas contaba con una población de 601,123 habitantes, con tasa de crecimiento de $1.8 \%$. En ese tiempo se planeaban para la ciudad tres desarrollos importantes plasmados en el Plan Culiacán, planteados por las instancias municipales y estatales. Estos tres desarrollos urbanos eran el Centro Cívico, Tres Ríos y Culiacán del Sur, este último convirtiéndose en La Primavera. Ya que el esquema sectorial se encontraría integrado con un sistema vial metropolitano, donde se clasificaban vialidades periféricas, primarias, secundarias de primer orden, secundarias de segundo orden, con nodos primarios, secundarios y terciarios que movilizarían a la ciudad. Se planteaba que el desarrollo urbano Culiacán del sur concentraría el porcentaje más alto de población de 1994 al 2015, sin embargo el área de expansión del suelo se propone como una zona media, ya que la zona poniente, correspondiente al desarrollo urbano centro cívico era la de mayor expansión, es importante destacar que éste sector es el que muestra un mayor grado de consolidación urbana, contrastante con otras zonas de la ciudad.

Durante los años noventas las colonias dejan de ser la unidad habitacional principal de crecimiento de la ciudad y tienen mayor auge los fraccionamientos, al convertirse en un negocio inmobiliario fraccionando el suelo para generar vivienda mínima promovida a partir de créditos de financiamiento para población de estatus medio.

El énfasis del desarrollo habitacional recae en los fraccionamientos cerrados, éste tipo de desarrollos, por lo general se localizan en las periferias, son amurallados y proponen elevar la calidad de vida de sus habitantes a través de elementos medio ambientales y de convivencia social en su interior. Rincón de Guadalupe, ubicado en las periferias y en terrenos de topografía elevada, fue el primer fraccionamiento cerrado en la ciudad fundado a finales de los setentas, durante los noventas los fraccionamientos cerrados adicionan como atractivo para los residentes diversos equipamientos en su interior retomando con ello, los planteamientos del nuevo urbanismo en el que se privilegian las cualidades medioambientales de los lotes y se les dota de los equipamientos e infraestructuras necesarias para una alta calidad de vida en el interior.

A mediados de los noventas el proyecto de La Primavera se presenta como un desarrollo habitacional dirigido a estratos de altos ingresos, planeado integralmente, en el cual se incluirían diversos equipamientos, centros de empleo, comercio, servicios y ocio, lo que fortalecería la economía local y dinamizaría el desarrollo urbano en el sur de la ciudad. Asimismo, en torno a La Primavera se ubican contrastes, como los fraccionamientos cerrados de interés social, colonias marginadas de servicios progresivos y un amplio sector de bodegas sobre las vialidades principales.

La expansión de la ciudad mediante los fraccionamientos cerrados se presenta de manera difusa, es decir se ubican en el espacio urbano y suburbano de forma aislada al contexto inmediato, existiendo a la fecha en Culiacán 93 desarrollos de tipo cerrado, dentro de los cuales el proyecto La Primavera es el único que se ubica como un gran subsistema denominado por sus creadores como ciudad satélite.

Las intervenciones urbanas a gran escala, como es el caso de La Primavera, a través de mecanismos para el mejoramiento de zonas específicas, dotan de infraestructuras y 
equipamientos que fomentan el crecimiento y densificación urbana. El desarrollo urbano La Primavera se ciñe a lo establecido en leyes de tipo municipal, estatal y federal vigentes en la época de autorización. Entre concesiones y permisiones el desarrollo ha realizado operaciones urbanas que han propiciado la expansión de este sector. Es importante destacar que en la planeación del desarrollo se ha propuesto una morfología basada fundamentalmente en el modelo urbano norteamericano y en el chino, creando un híbrido interesante en cuanto a planeación del tipo habitacional.

\subsection{Proceso de expansión urbana}

La expansión del desarrollo urbano en su interior, ha sido relevante, el plan maestro se encuentra registrado el $70 \%$ aproximadamente, es decir catastralmente cuenta con registros prediales de isla del oeste, barrio san Agustín y barrio San Luis ${ }^{19}$. Ya que del programa arquitectónico planteado falta desarrollar: el barrio Isla del Este y el barrio San Anselmo. Este plan maestro, ya cuenta con el equipamiento planteado que consta de la Plaza de la iglesia, Centro Comercial en proceso, Campo de Golf profesional, Parque Industrial y el Dique La Primavera.

La expansión de La Primavera al interior ha cumplido con sus objetivos, sin embargo al exterior esta expansión urbana se ve enmarcada en un circulo de segregación fomentando el proceso expansivo, registrándose la aparición de fraccionamientos sobretodo cerrados al exterior de La Primavera con expectativas de aumentar el valor del suelo aprovechando la infraestructura existente, sin embargo un fraccionamiento cerrado origina vialidades de conexión y servicios sólo a su interior con inversión gubernamental muy alta, lo cual origina un alto contraste con el territorio circundante.

La expansión urbana por fraccionamientos a partir de La Primavera, ha sido muy marcada en los últimos cinco años, debido al auge mercantil de viviendas en el estado de Sinaloa y políticas establecidas por el gobierno federal. La Primavera se encuentra rodeada por fraccionamientos de tipo progresivos, específicamente los más marginados de la ciudad, desde fraccionamientos de interés social hasta colonias populares ya asentadas con servicios progresivos. Así mismo, a principios de este nuevo milenio el gobierno municipal autorizó dos fraccionamientos que desde sus inicios fueron cerrados arbitrariamente, los cuales no cuentan con los elementos símbolo de un fraccionamiento cerrado, tampoco cuentan con la autorización de régimen en condominio, puesto que la expectativa de elevar la calidad de vida de sus pobladores es muy baja y nula en ocasiones.

Figura 4 Expansión urbana por unidad de población del sector sur de la ciudad de Culiacán

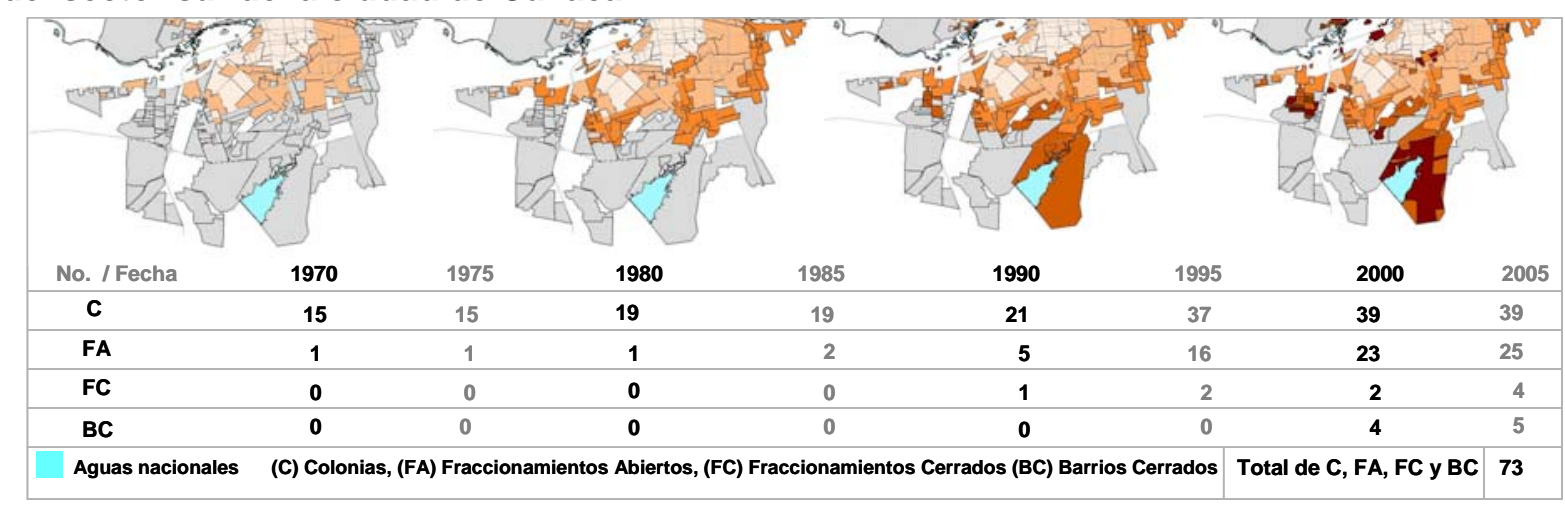

de Culiacán. Consultas predios en plano catastral. Consultado el 20 de Noviembre de 2005. En: http://www.catastro.culiacan.gob.mx/ 
En la figura 4, se señala la expansión urbana por unidad habitacional del sector sur de la ciudad de Culiacán, donde destacan al año 2000, los fraccionamientos cerrados Vista hermosa y Capistrano como los dos concebidos como privadas que manejan un concepto comercial recurrente en la ciudad en los últimos años, con baja calidad y altas promesas publicitarias. Lo cual fundamenta la segregación de este sector de la ciudad, originando problemas urbanos como "la inseguridad" 20 , mismos que son difíciles de solucionar después de densificarse la zona, en entrevista con habitantes de los fraccionamientos cerrados en torno a La Primavera, comentaban que no eligieron vivir cerca de La Primavera, entendamos como concepto, ya que en esta misma entrevista, fundamentaron que eligieron vivir en este sector y en estos fraccionamientos porque contaban con infraestructura y equipamientos, y les permitía sentirse seguros el tener vigilancia nocturna en las vialidades de acceso a La Primavera, así mismo los muros de sus fraccionamientos les permitía separarse de las colonia del alrededor y evitar cualquier tipo de problemas, ya que podían ser afectados por la delincuencia. Es importante mencionar, que los índices de violencia en estos fraccionamientos es el promedio de la ciudad, sin embargo el tipo de delitos que se encuentran registrados al interior de La Primavera ellos no los han tenido, como son homicidios dolosos.

La delimitación del sector de expansión de La Primavera Boulevard Emiliano Zapata al norte, Boulevard Jesús Kumate Rodríguez al poniente, al nororiente por la Av. Manuel J. Clouthier y Boulevard Ing. Guillermo Batíz Paredes, al oriente por la Calzada Heroico Colegio Militar y al sur por el Libramiento Sur Benito Juárez.

\section{Primera década: los setentas}

Durante esta década surgen una serie de colonias de tipo popular concentradas sobretodo en el sector sur de la ciudad, como características centrales, los escasos servicios básicos, infraestructura y equipamiento; surge a finales los setentas el primer fraccionamiento abierto del sector sur, denominado San Rafael, el cual no impulsa el desarrollo en las anteriores colonias mismas que hasta la fecha no cuentan con la incorporación de infraestructura y equipamientos en gran parte del sector.

\section{Segunda década: los ochentas}

Durante esta década continua la proliferación del número de colonias. Asimismo, aumenta el número de fraccionamientos abiertos y con ello surgen fraccionamientos como Jardines del Valle y Barrancos Infonavit. Destaca en 1986 el surgimiento del primer fraccionamiento cerrado, Villa Bonita, el cual surge con unas murallas en su entorno como defensa a riesgos naturales y en la actualidad continua con estos muros incorporándolo como eslogan mercantil de privacidad y de seguridad.

\section{Tercera década: los noventas}

En 1998 se da origen a la aprobación a partir de un fideicomiso del proyecto denominado Alfa con superficie total de $378,540.00 \mathrm{~m} 2$ para fraccionar 1492 lotes de $125 \mathrm{~m} 2$ cada uno de ellos, mismo que representa una oportunidad para la administración municipal para adquirir suelo barato y convertirlo en un fraccionamiento de lotes para integrar a un sector marginado de la sociedad, cuya característica consiste en no tener la posibilidad de adquirir un crédito para vivienda, en muchas de las ocasiones no poder acceder a un trabajo con una pago salarial mínimo. De la misma manera surgen una serie de colonias populares que acrecientan el

\footnotetext{
${ }^{20}$ María Alejandrina Rodríguez Lares (Trabajadora Social Jubilada, 47 años), usuaria de Villa Bonita, en cuestionario "Cédula de Entrevista de Fraccionamientos Cerrados", realizado en Casa Habitación: Villa Bonita, fecha de realización del cuestionario Mayo 13, 2006; Jesús Humberto Muñoz García (Licenciado en Contaduría Pública, 40 años), usuario de Villa Bonita, en "Cédula de Entrevista de Fraccionamiento Cerrados", realizado vía internet a correo electrónico Jmunoz@mapfre.com.mx, fecha de respuesta Abril 6, 2006.
} 
porcentaje de la zona. Y como principio de un desarrollo urbano independiente del crecimiento urbano que ha concebido el sector sur de la ciudad se aprueba el desarrollo urbano La Primavera, dando inicio a la construcción del desarrollo habitacional barrio La Isla y El mar.

\section{Cuarta década: nuevo milenio}

Durante esta década se consolidan la mayoría de las colonias y fraccionamientos de tipo abierto, con un surgimiento de fraccionamientos cerrados en el entorno al desarrollo de La Primavera; aparecen colonias como Los Girasoles, fraccionamientos abiertos como Lomas de San Isidro, Hacienda del Valle, Rincón del Valle, fraccionamientos cerrados como Capistrano Residencial y Hacienda Molino de Flores, asimismo se desarrollan otros barrios como San Luis, Isla del Oeste, San Agustín y el barrio comercial en La Primavera.

En la actualidad, el fenómeno de expansión urbana en el sector sur representa el $17.3 \%$ de todos los desarrollos habitacionales del resto de la ciudad.

\subsection{Operaciones urbanas}

Las operaciones urbanas como mecanismos para el mejoramiento de una zona de gran dimensión para su desarrollo determinada bajo el concepto de suelo creado, orientado a una transformación por intervenciones que dotan de infraestructura y equipamientos urbanos que permitan una posibilidad para su densificación.

El desarrollo urbano La Primavera cuenta con fundamentos jurídicos, según lo establecido en leyes de tipo municipal, estatal y federal vigentes en la época de autorización. Se señala la Constitución Política de los Estados Unidos Mexicanos, con relación al artículo 27; la Ley General de Asentamientos Humanos; la Ley de Desarrollo Urbano del Estado de Sinaloa y la Ley de Desarrollo de Centros Poblados del Estado de Sinaloa.

La Primavera representa un desarrollo urbano detonante de operaciones urbanas pero a su interior, ya que al exterior representa solo el 1.09\%. Este desarrollo es simbólico como fraccionamiento cerrado ya que representa en la actualidad manifestaciones y servicios a su interior con efectos directos sobre su entorno después de sus murallas. Entre concesiones y permisiones el desarrollo ha realizado operaciones urbanas que han fundamentado cambios en la ciudad, sobretodo han originado la expansión de este sector. Es importante destacar que el desarrollo se puede posicionar en el mundo a partir de sus operaciones urbanas, ya que el plan maestro que lo fortalece se ha convertido en un híbrido con un predominio morfológico basado en dos modelos fundamentales, el modelo americano y el modelo chino. Esto debido a las operaciones urbanas que se han realizado en las diversas etapas del desarrollo.

Algunas de las operaciones urbanas que se han tenido que realizar en La Primavera son para satisfacer su demanda de agua potable, la construcción de un tanque de almacenamiento similar al tanque San Lorenzo, con capacidad de 7,500 m3. Este nuevo tanque, que será construido por la JAPAC, se ubicará en un terreno predispuesto y se alimentará a través del tanque existente desde la planta potabilizadora San Lorenzo. A partir del nuevo tanque y desde el acceso principal se iniciará la ramificación de la tubería que alimentará a toda La Primavera, la cual tendrá un gasto total de 300 Ips.

La topografía del terreno hace necesario la construcción de un tanque de almacenamiento y un 
cárcamo de bombeo para cubrir parte de las megamanzanas situadas al este del Desarrollo.

En el proyecto ejecutivo de cada etapa se desarrollarán las redes de agua potable y un sistema de drenaje que se compondrá de dos colectores principales: el Colector Sur III, (capacidad de 1,250 lps y un diámetro de $107 \mathrm{~cm}$ ). Actualmente se encuentra en operación y cruza el predio por la parte occidental del lago, éste recogerá todas las descargas de esa zona para continuar su recorrido fuera del predio. Por el lado oriente, se construirá otro colector de características similares al Sur III, que servirá a esta zona. Ambos colectores descargarán al dren Chiricahueto y éste llegará en un futuro próximo, a la planta de tratamiento que el municipio planea construir a través de la JAPAC.

\section{Manifestaciones urbanas}

La ciudad se ha transformado y tomado nueva forma, debido al crecimiento urbano propiciado en los últimos diez años, a partir de la iniciativa de crear suelo urbano aledaño al ranchito y la primavera, transformo el sector. Durante los años noventas el sector era una reserva y suelo rural que no era poco trabajado y abandonado, el dique era una manifestación natural aislada de la ciudad que cubría el riego de la zona ejidal y los poblados cercano. La ciudad tenía una forma continua ligada a una sola carretera en su extremo sur y otra hacia el norte, La Primavera inicia como una cédula independiente de la ciudad abierta.

Pero a partir de 1998, que se plantea la creación del desarrollo urbano La Primavera se inicia la continuidad de las primeras conexiones entre la ciudad y el desarrollo a través de la entonces prolongación de la avenida Álvaro Obregón, la cual actualmente es la vía principal del centro de la ciudad abierta con el desarrollo. Se da continuidad a la construcción de la continuidad de la Av. México 68 con la que se crea el primer acceso al desarrollo y más tarde se conecta a través un puente de desnivel de conexión entre el acceso del desarrollo y la ciudad abierta.

Pero en estos ocho años La Primavera ha propiciado la expansión por colonias progresivas, fraccionamientos abiertos y dos fraccionamientos cerrados todos ellos de interés social. Desde el proyecto alfa conformado por colonias del alto impacto en la ciudad abierta por corresponder al sector más marginado, hasta fraccionamientos abiertos como Prados del Sur, Rincón del Parque, Prados del Sol, Los Girasoles, Lomas de San Isidro y Los Portales, asimismo, fraccionamientos de tipo cerrados como Villa Bonita y Capistrano. Todos estos desarrollos son el vestíbulo al acceso de La Primavera y conexión con la ciudad abierta, así mismo se ha visto fomentado en el aprovechamiento de la infraestructura creada por el desarrollo. Sin embargo, el subsistema inicial se encuentra en proceso de expansión en su entorno, ya que cuenta con mayor posibilidades de expandirse el desarrollo que la creación de fraccionamientos aledaño ya que los servicios son difíciles de cubrir y los riesgos urbanos son mayores en el sector La Primavera que en el sector de la ciudad abierta, ya que la cota topográfica a originado un dinamismo en sus alturas del límite de la carretera hacia el dique.

La morfología y diversas manifestaciones urbanas han detonado el sector sur entorno a La Primavera, destacando su ubicación entre colonias populares, de servicios progresivos y fraccionamientos de interés social, es decir la mezcla entre estatus económicos es nula, ya que la dinámica al interior es para el desarrollo de la clase alta y en su entorno se denomina marginal y estatus bajo. Esta segregación se manifiesta en los fraccionamientos abiertos y cerrados con un alto grado de violencia por robos domiciliarios sobretodo, así mismo destacan otros eventos delictivos entorno, como homicidios, violencias intrafamiliar, entre otros delitos que fomentan las altas murallas y sistemas de seguridad de La Primavera.

El sector esta demarcado por segregación por la falta de servicios y oportunidades 
económicas; es decir, en torno a La Primavera no se privilegia la exclusividad, la privacidad o la seguridad, el sector destaca por contener indicios de segregación, simulación e inseguridad.

Con ello se manifiesta que el impacto por inseguridad es de un grado menor en La Primavera que en la ciudad abierta, pero esto no los excluye de no tener que luchar diariamente por una seguridad que todos deseamos en nuestras ciudades, aunque son principios de los diversos delitos.

\section{Impacto de La Primavera en el crecimiento de la ciudad}

El desarrollo de La Primavera se presenta como un elemento autónomo a la ciudad de Culiacán, tanto por su gran extensión, como por las pretensiones plasmadas en el proyecto en el que se plantea una multifuncionalidad dirigida a satisfacer las necesidades de estratos altos de la comunidad. Pero sin duda lo ambicioso del proyecto radica en la inclusión de zonas industriales apoyadas en la explotación de importantes recursos naturales de la ciudad que ahora se encuentran privatizados dentro del conjunto.

La Primavera tiene un impacto directo sobre todo la ciudad, pero en específico en el sector sur de Culiacán, en el análisis del área urbana ocupada y concentración de población.

El esquema urbano y arquitectónico de La Primavera presenta de entrada una dislocación con el Plan de Desarrollo Urbano de la ciudad, ya que si bien en éste se establecía la zona como de potencial crecimiento, el espacio ahora construido rompe con el entorno de manera tajante exclusión social, aislamiento físico y seguridad privada-. Además el conjunto aprovecha la riqueza de los recursos disponibles y en ningún caso retribuye a la zona con la facilitación de infraestructura urbana a las colonias aledañas, lo que refuerza su concepto de comunidad cerrada y aislada por completo del contexto, como es el caso de "la estructura vial" ${ }^{21}$ entre La Primavera y el resto de la ciudad, mismo que confirma el experto en proyectos del Instituto Municipal de Planeación Urbana, las grandes preocupaciones para los habitantes de La Primavera son la creación de vialidades de acceso rápido, que los mantengan seguros al interior, que les permitan un rápido y seguro traslado.

Como comentábamos anteriormente el proyecto teóricamente se apoya en corrientes internacionales de planeación urbana, como el nuevo urbanismo, pretendiendo ser una unidad autosuficiente y sustentable. Sin embargo sus características lo ubican entre los proyectos de comunidad cercada más emblemáticos de Latinoamérica.

Con manifestaciones urbanas como la conformación de un nuevo estilo de vida, la seguridad y

\footnotetext{
${ }^{21}$ El Implan tiene Proyectos Estratégicos como "el Plan Estratégico de Ordenamiento Territorial y el Plan de Movilidad de la ciudad de Culiacán, donde un punto básico es el evitar la segregación, (...) porque algo de lo que adolece la planeación normativa que ha venido surgiendo es esa falta de integración (...)" como en la estructura vial. "Al interior de La Primavera se tiene conceptualmente un desarrollo de vialidades interesante, que permite tanto el uso del vehículo público, como de métodos alternos como ciclopistas o espacios peatonales, más en su relación hacia el exterior ha tenido que cuidar las arterias que conectan ese gran desarrollo, por no resolver adecuadamente las necesidades de movilidad de los habitantes de La Primavera, pero desarticuladamente en el corto plazo del resto de la mancha urbana en la zona sur, (...) sumado a esto La Primavera se desarrolló posterior al borde que representa La Costerita como vialidad federal de tráfico pesado, un ejemplo claro es que la entrada a La Primavera representa una inversión muy fuerte, que requiere de los tréboles por medio de gasas para poder generar una accesibilidad a ese fraccionamiento, (...) está claro que un desarrollo habitacional como La Primavera que tiene características de las ciudades satélites ocupa de infraestructura vial que la conecte con el centro de la mancha urbana y pienso que en ese sentido no hubo una corresponsabilidad con el resto de la mancha urbana". Alberto Gerardo Medrano Contreras, Coordinador de Proyectos Estratégicos del Instituto Municipal de Planeación Urbana. Entrevista. Culiacán, Sinaloa, México: Oficina del Implan, Junio 16, 2006 (grabación), 14:15-15:25 hrs.
} 
exclusividad a su interior, mismas que son discutidas en la actualidad al encontrarse entre una serie de problemas urbanos desde sus inicios hasta nuestros días. Es reconocido que el desarrollo urbano impacta al interior conmocionando con una alta segregación urbana, detalle de ello es en el mercado urbano claro ejemplo de los problemas de ordenamiento e integración de diversos sectores de la ciudad a un todo, es discutible que La Primavera al no ser sustentable a su interior cubre necesidades al exterior por ello, se encuentra ligada principalmente al centro de la ciudad abierta.

Uno de los grandes impactos es el costo del suelo en la ciudad abierta entorno a La Primavera, cuando el costo por metro cuadrado en el interior es diez veces más costoso económicamente, socialmente la cuota es incomparable, el concepto que fundamenta al desarrollo urbano en la actualidad se conceptualiza por sus creadores como una ciudad satélite, se basa en la legitimidad social y posicionamiento económico. Aunque el proyecto inicial desarrollado por la consultoría norteamericana PBR es uno de los mejores proyectos a nivel internacional, en la actualidad La Primavera se encuentra en menos del cincuenta porciento del desarrollo, con principios arquitectónicos sobretodo muy diferentes al proyecto inicial y de tipo urbano rescatables como uno de los primeros desarrollos urbanos tipo ciudad cerrada planeados por primera vez en la historia del estado de Sinaloa y como uno de los mejores diseños urbanos a nivel nacional. Sin embargo es importante destacar que el desarrollo no impacta como fue proyectado ni a un cincuenta porciento, por ello es importante reforzar el proyecto inicial para confirmar la visión de ciudad y poder cumplir con líneas lejos de cumplir para la fecha propuesta, el 2010. Algunos de estas estrategias factibles de convertirse en líneas de acción para llevar a cabo son tanto al interior como exterior del desarrollo, ya que es conocido que uno de los grandes impactos es la infraestructura provocada para acceder al desarrollo, mismo que ha proporcionado servicios básicos al entorno de las vialidades de acceso, lo cual no indica un suelo social, público o rentable que eleve la calidad de vida de los habitantes entorno al desarrollo, sino se han encontrado altos niveles de segregación socio-espacial entre las dos clases sociales extremas, especulación del suelo, inseguridad para los habitantes al interior, fraccionamientos cerrados y abiertos aledaños. Asimismo, el impacto urbano y social se ha confrontado con los habitantes en pobreza marginal reubicados en el "proyecto alfa"22, mismo que hasta la actualidad no cuenta con los servicios básicos a pesar de haberse creado una infraestructura de paso antes de llegar a La Primavera. Es decir, los impactos no han conformado un equilibrio en la ciudad, conformando poco impulso al desarrollo y poca inversión en el sector sur de la ciudad, al encontrarse el crecimiento urbano de inversión en el sector norponiente y surponiente de la ciudad.

En entrevista con representantes de la administración federal, de la Secretaría de Desarrollo Social, en Sinaloa, comentaban que los problemas de mayor impacto en la ciudad por este tipo de desarrollos con muros, son la concentración de pobreza, ya que buscan mejorar su estatus o calidad de vida, al asentarse en la mayoría de las ocasiones en torno a desarrollos urbanos cerrados, como son los fraccionamientos cerrados, debido que jalan diversos servicios, entre lo que destaca la creación de grandes vialidades y equipamientos en torno a ellos, como es el caso de La Primavera y los desarrollos alrededor de ella.

\footnotetext{
22 "El proyecto alfa correspondía a una reserva que pretendía producir plusvalía a través de la venta de lotes tipo para gente con recursos escasos y con ello poder sostener dicho proyecto. Sin embargo, los lotes fueron vendidos a personas que no los ocuparon y la inversión en infraestructura no se aprovecha, ya que dichos servicios se instalaron en lotes baldíos y el terreno es demasiado caro para costear dichos servicios. El impacto del proyecto alfa, es el no cumplir con el objetivo planteado de dar vivienda para gente pobre, lo cual ha ocasionado problemas sociales de segregación social, con respecto a los otros fraccionamientos alrededor del proyecto, ya que no cuentan con servicios de agua, drenaje, pavimentación y equipamientos como escuelas; todo esto originando mayor número de delincuentes en la ciudad, por la falta de oportunidad.". Jesús Manuel Rodríguez Lares, Subdelegado de Desarrollo Urbano, Ordenación del Territorio y Vivienda, Secretaria de Desarrollo Social. Entrevista. Culiacán, Sinaloa, México: Oficina del Subdelegado, Mayo 19, 2006 (grabación), 20:00-20:45 hrs.
} 
La expansión urbana por fraccionamientos cerrados y la ciudad cerrada La Primavera han otorgado manifestaciones como la exclusividad y la seguridad. Determinando un nuevo estilo de vida para algunos de los habitantes de la sociedad culiacanense, siendo ambas manifestaciones un impulso de búsqueda para mejorar la calidad de vida dentro de la ciudad abierta, siendo estos 93 fraccionamientos cerrados el $22 \%$ del total.

Figura 5 Fachada de La Primavera

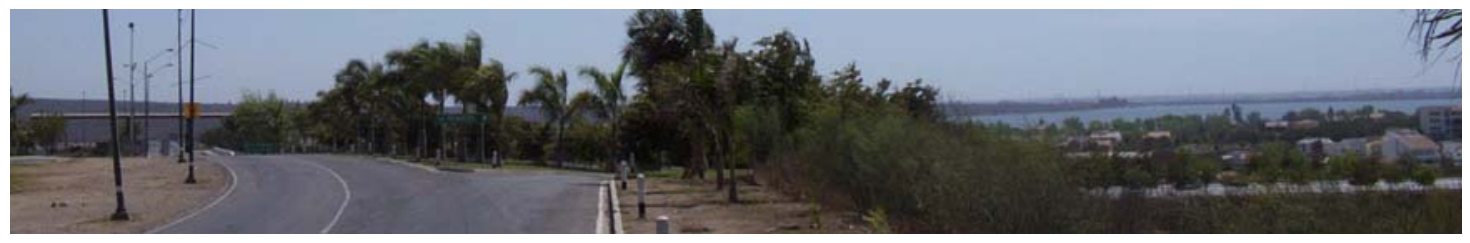

Fuente: Propia (2006).

La Primavera se proyectó para el 2011 bajo la transformación de suelo rural a suelo urbano de 819.82 ha para 7,957 lotes para 55,000 habitantes con usos para plaza de la iglesia, centro comercial, barrio habitacional San Agustín, San Luis, isla del oeste, isla del este, San Anselmo y zona comercial, campo del golf, parque industrial, el dique la primavera.

Para el 2005 la denominada ciudad cerrada La Primavera se ha consolidado por un barrio zona industrial, barrio habitacional isla y el mar, isla del oeste, San Luis, San Agustín, el barrio zona comercial y el dique la primavera, como se visualiza en la figura 5.

Así como se da un proceso de expansión al interior de la ciudad cerrada por cinco barrios cerrados, se expande al exterior por cuatro fraccionamientos cerrados y el incremento de equipamientos de 1970 al 2005 se ha dado principalmente en escuelas y unidades comerciales, sin embargo los edificios de salud son otro de los giros demandados. Siendo la concentración de población en área urbana entorno a la ciudad cerrada de 5,756 habitantes y con un área urbana ocupada de 94.86 hectáreas.

Se destaca que dentro de los 93 fraccionamientos cerrados se contempló para el análisis inicial al desarrollo urbano La Primavera, este desarrollo se denomina por sus inversionistas como Ciudad Satélite. A partir de esta denominación de sus socios como una nueva ciudad dentro de la gran ciudad, se conceptualiza en este estudio a La Primavera como Ciudad Cerrada, al ser el único desarrollo en la ciudad donde se genera en gran porcentaje de suelo urbano creado delimitado por murallas, al contar con barrios conformados como núcleos de desarrollo al interior de tipo amurallado, contar con equipamiento de alto impacto como una zona industrial, comercial, religiosa, educativa, de recreación, entre otras en proyección, vialidades de desplazamiento rápido de conexión con equipamientos de gran impacto como aeropuerto y oficinas administrativas. También cuenta con manifestaciones y problemas urbanos que impactan a La Primavera tanto al interior como en su entorno, en correspondencia a su superficie. Siendo estas de menor impacto en cada uno de los otros fraccionamientos cerrados del resto de la ciudad.

La Primavera al manifestarse con mayor impacto debido a la dimensión del proyecto, incluye barrios cerrados, equipamiento e infraestructura cubierto para todo el desarrollo, ha sido denominado por sus socios como una ciudad satélite, por ello estando bajo el análisis conceptual de las ciudades de Latinoamérica, La Primavera deja de ser un común fraccionamiento cerrado para convertirse en una nueva centralidad amurallada, conceptualizada como una ciudad cerrada. Teniendo gran impacto en la ciudad pero en dimensión a su superficie. Por ello, La Primavera a pesar de no ser consolidada al $100 \%$ a su interior, en el exterior entorno a ella, impacta el proceso de segregación. Aunque la lógica 
debería ser que entre mejores servicios cubren el interior de la ciudad cerrada, el entorno de este desarrollo fuera de menor segregación, sin embargo como otras ciudades de Latinoamérica al existir suelo posible de urbanizarse entorno al desarrollo, se crean asentamientos de tipo irregular y también se consolida con fraccionamientos improvisados 0 con un concepto no fundamentado en el proyecto de cada una de las inmobiliarias, sino sustentado en el nuevo estilo de vida fundamentado en La Primavera.

El impacto que la ciudad cerrada La Primavera tiene en el sector sur es considerable, ya que aunque en una mínima extensión continua con su expansión urbana, este desarrollo se encuentra fomentando la densificación tanto a su interior como en el exterior, mostrándose así el impacto más fuerte por tendencia expansión-densificación al sur de la ciudad. Ya que cerca de La Primavera se han construido cinco fraccionamientos abiertos, cuatro fraccionamientos cerrados y se han expandido los desarrollos habitacionales conformados por poblados, colonias populares, colonias progresivas, el suelo entorno al desarrollo se encuentro expandiéndose con una mezcla de clases sociales que no son cubiertas según sus necesidades, pero es importante destacar que los habitantes de la ciudad, los más desprotegidos buscan elevar su calidad de vida a través de mejorar sus servicios básicos, mismos que son cubiertos parcial o totalmente por la conexión realizada del área urbana cercana a la periferia donde se encuentra La Primavera, ya que para su creación fue cubierta la conexión de servicios básicos, así mismo las vialidades fueron generadas como vialidades rápidas debido al desplazamiento requerido en su momento, en la actualidad se cuenta con principios de inaccesibilidad al sector y con problemas de movilidad.

El desarrollo de La Primavera se presenta como un elemento autónomo a la ciudad de Culiacán, tanto por su gran extensión, como por las pretensiones plasmadas en el proyecto en el que se plantea una multifuncionalidad dirigida a satisfacer las necesidades de estratos altos de la comunidad. Pero sin duda lo ambicioso del proyecto radica en la inclusión de zonas industriales apoyadas en la explotación de importantes recursos naturales de la ciudad que ahora se encuentran privatizados dentro del conjunto.

Los impactos urbanos en La Primavera han sido determinantes en sus objetivos del Plan Parcial del Desarrollo Urbano de 1998, de la siguiente manera: La oferta de suelo destinada a usos habitacionales, educativos, culturales, recreativos, turísticos e industriales, se utiliza para posibilitar la realización de obras que se requieran, especialmente vialidades. Aunque el desarrollo es un desarrollo habitacional en mayor porcentaje, pero aún no es una referencia turística.

Complementario al objetivo anteriormente, se expone el enlazar en forma equilibrada todos los puntos del desarrollo mediante vialidades peatonales, vehiculares y navegables, lo cual es cumplido equitativo a lo que hasta el momento se ha construido al interior.

Las actividades de vivienda, educación, deporte, recreación y trabajo, no son del todo cumplidas ya que sus barrios al interior se encuentran cerrados y eso impide la accesibilidad y movilidad en el desarrollo de una forma armónica, asimismo la integración en forma armónica de actividades de trabajo, no es para todos, la mayoría al interior de La Primavera trabaja al exterior en la ciudad abierta.

El objetivo de mejorar la calidad del medio ambiente con la reforestación y el rescate y mantenimiento del lago, canales y arroyos, cumplen en primer término sin embargo no son sustentables para la ciudad en su totalidad, se encuentra en proceso. Ejemplo, de ello es el barrio industrial ubicado al interior del desarrollo.

El propósito de atraer inversiones que fortalezcan la economía de Culiacán y del Estado de Sinaloa, esta en proceso ya que al contar con un barrio destinado a la industria con inversiones 
extranjeras permite la competitividad con otras ciudades, así como la generación de textiles de exportación.

El último concepto sobre si La Primavera es un nuevo modelo de desarrollo urbano, es un desarrollo urbano con dimensiones de una ciudad cerrada a nivel nacional, sin embargo a nivel Latinoamérica se cuenta con un concepto semejante y con una consolidación e impactos mayores a La Primavera.

Pero es real que La Primavera a pesar de no ser un conjunto urbano para todos, es una ciudad cerrada para unos cuantos que puedan acceder a ella, mismos que no contaban con la oportunidad de compartir espacios recreativos en la ciudad abierta, lo cual es aceptable por los socios de dicho desarrollo. Por ello el proceso de investigación arroja la segregación por déficit de equipamientos sobretodo de áreas recreativas que permitan la accesibilidad a los habitantes de colonias populares y fraccionamientos abiertos, donde existe mayor número de concentración poblacional.

\section{Bibliografía}

Amendola, Giandomenico. La Ciudad Postmoderna: Magia y miedo de la metrópolis contemporánea. Madrid: Celeste ediciones, c2000, 1era. Edición, p.480.

Comisión Nacional del Agua. Comunicado de inicio de procedimientos de determinación de faltas e imposición de sanciones a la empresa KYARA, S.A. de C.V. Agosto 20, 2002. Culiacán, Sinaloa, México: Gerencia Regional Pacífico Norte, Subgerencia de Administración del Agua, Expediente No. VI-PNI-2002-III-007, Oficio No.BOO.00.R04.04-0679/3443.

Constructora MegaPark. Modelos de viviendas de fraccionamientos cerrados. Culiacán, Sinaloa, México. Mayo 8, 2006. En: http://www.megapark.com.mx/

Coppel Luken, Enrique. Entrevista a socio de La Primavera: documental y sin grabación. Culiacán, Sinaloa, México: Oficinas Coppel. Junio 19, 2006. 17:00-17:30 hrs.

Crónica del Municipio de Culiacán. Expediente Desarrollo Urbano La Primavera. Culiacán, Sinaloa, México: AXYA, S.A. de C.V., Oct. 1997, Acta 60, Punto VI: a.

Gerente General JAPAC. Contratos adicionales al de prestación de servicios, comodato por el uso gratuito y temporal de la Planta Potabilizadora y el otro por prestación de servicios con la empresa filial.

H. Ayuntamiento de Culiacán. Actas diversas: aprobaciones y recepciones. Culiacán, Sinaloa, México: Cabildo del H. Ayuntamiento, 1970-2005.

. Expediente de La Primavera: Barrio San Agustín. Diciembre 8, 2000. Culiacán, Sinaloa, México: Cabildo del H. Ayuntamiento, Acta No.53.

. Expediente de La Primavera: Barrio San Luis. Mayo 20, 2002.

Culiacán, Sinaloa, México: Cabildo del H. Ayuntamiento, Acta No.40.

$\mathrm{H}$. Congreso del Estado Libre y Soberano de Sinaloa. Ley de desarrollo urbano del estado de Sinaloa. Septiembre 1, 2004. Decreto №659, P.O. №105.

Plan Parcial de Desarrollo Urbano La Primavera. México: Gobierno del Estado de Sinaloa, c1998, Periódico Oficial "El Estado de Sinaloa" No.150, p32.

Janoschka, Michael. Nordelta: Ciudad Cerrada. El análisis de un nuevo estilo de vida en el gran Buenos Aires. Barcelona: V Coloquio Internacional de Geocrítica. Mayo 16-30, 2003, p.16. En: http://www.faudi.unc.edu.ar/mgdh/mutaciones/janoschka2003.doc

Medrano Contreras, Alberto Gerardo: Coordinador de Proyectos Estratégicos del Instituto Municipal de Planeación Urbana. Entrevista con grabación. Culiacán, Sinaloa, México: Oficina del IMPLAN, Junio 16, 2006, 14:15-15:25 hrs.

Méndez Sáinz, Eloy. Vecindarios defensivos latinoamericanos. Los espacios prohibitorios de la Globalización. Revista Perspectivas Urbanas / Urban perspectivas, № 4, p.17. Consultado el 1 de enero de 2005. Disponible en: https://e-revistes.upc.edu/bitstream/2099/584/2/art04-2.pdf 
Muñoz García, Jesús Humberto: Licenciado en Contaduría Pública, 40 años, usuario de Villa Bonita. Cédula de Entrevista de Fraccionamiento Cerrados: Vía Internet a correo electrónico Jmunoz@mapfre.com.mx, Abril 6, 2006.

Rodríguez Chumillas, Isabel y Ruiz-Gómez, Manuel Mollá. La vivienda en las urbanizaciones cerradas de Puebla y Toluca. Universidad de Barcelona: Revista electrónica de Geografía y Ciencias Sociales: Scripta Nova, Agosto 1, 2003, Vol. VII No 146, p.16. SIN: 1138-9788.

Rodríguez Lares, María Alejandrina: Trabajadora Social Jubilada, 47 años, usuaria de Villa Bonita. Cédula de Entrevista de Fraccionamiento Cerrados: En Casa Habitación Villa Bonita, Mayo 13, 2006.

Rodríguez Lares, Jesús Manuel: Subdelegado de Desarrollo Urbano, Ordenación del Territorio y Vivienda, Secretaria de Desarrollo Social. Entrevista con grabación. Culiacán, Sinaloa, México: Oficina del Subdelegado, Mayo 19, 2006, 20:00-20:45 hrs.

Sassen, Saskia. Los espectros de la globalización. Argentina: Fondo de Cultura Económica ediciones, c2003, 1era. Edición, p. 276.

Traducido del Charter of the New Urbanism. Aprobado por El Congreso para el Nuevo Urbanismo: Carta del Nuevo Urbanismo. Noviembre 20, $2005 . \quad$ En: http://www.cnu.org/pdf/Carta espanol.pdf Unidad de Catastro Municipal de Culiacán. Consultas predios en plano catastral. Noviembre 20, 2005. En: http://www.catastro.culiacan.gob.mx/ 